\title{
Life Kinetik Training in Improving the Physical Condition of Football Athletes
}

\author{
Komarudin Komarudin* \\ Department of Sport Coaching \\ Universitas Pendidikan Indonesia \\ Jl. Dr. Setiabudhi No. 229, Bandung 40154, Indonesia \\ *komarudin_pko@upi.edu
}

\author{
Patriana Nurmansyah Awwaludin \\ School of Post Graduate Studies \\ Department of Sports Education \\ Universitas Pendidikan Indonesia \\ Jl. Dr. Setiabudhi No. 229, Bandung 40154, Indonesia
}

\begin{abstract}
The physical condition training method for football athletes is still relatively low. In European countries, physical condition training is varied, even lead to multitasking training through life kinetik. So that the performance of athletes is better at performing tasks. The study aims to examine the effect of life kinetik in improving the physical condition of football athletes. This research method is experimental with a population of 50 athletes in UKM UPI. A sample of 40 people was taken randomly. Through random assignment, the sample was divided into two groups, namely the experimental group and the control group of 20 people each. The experimental group was given life kinetik training while the control was given conventional training. Physical condition instruments to measure the agility are using Side Step Test, and coordination using the whole body reaction test. This study used a pretest-posttest control group design. The data analysis technique used was the non-parametric man whitney test. The results showed that there were differences in the effect of life kinetik training and conventional training in improving the physical condition of football athletes. Life kinetik training is better than conventional training in improving the physical condition of football athletes.
\end{abstract}

Keywords-life kinetik; physical condition; football

\section{INTRODUCTION}

The top achievements of soccer athletes are determined by many factors including physical, technical, tactic, psychological abilities [1], including the brain's ability to regulate its own body's coordination. Lutz explained about a legendary talent of Argentinian, "he believes that while some, like Maradona, have an innate sense of intelligent movement [2] football athletes must have the ability to control the ball with their feet and the ability to shoot on goal accurately [3]. Besides that, the ability to control the ball with legs is not enough, players need speed to improve performance. Regarding the results of speed training research "sprint training at $90 \%$ of maximal sprint speed would enhance sprint performance in soccer players" [4]. The important thing about speed is stated in other studies such as speed is used as an evaluation material to look for potential football athletes since the beginning of his career [5]. Speed training is formed and given multi-dimensionally not only in adolescence but also before adolescence [6]. Knowing this explains, the football game requires speed.

Training conditions do not occur on their own, it requires the role of intelligence to address the challenges of the task as an athlete, and must be supported by the quality of skills, physical condition, and quality of the central nervous system to control complex tasks in football [7]. It was explained that support for human resources (brain) with his mind had to pay attention to important matters related to practicing the PsychologicalCognitive skill area which included such as; attention, anticipation, decision making, game intelligence, creative thinking, motor technical, skill, on personality are; selfconfidence, anxiety control, motivation, and concentration [8]. In addition, athletes need to be trained with the right training methods that demand complex motion abilities and multitasking mobility, through Life Kinetik training.

Life Kinetik Training is very important for football athletes because they are required to have physical abilities including speed, agility, movement coordination, physical fitness, and the ability to make decisions quickly. Therefore, Life Kinetik is in accordance with the patterns of movement and characteristics in football games. Life Kinetik training is orderly in the form of a combination of three aspects of training, namely training activities, cognitive challenges training, and visual perception training [9]. This training is a complex training method that requires athletes to move quickly, which is a forward, backward, left and right side, half left and right, which is full of the speed, agility, and coordination of each movement that must be performed in every form of Life Kinetik training.

The factual condition that occurs in Indonesia is that Life Kinetik training in improving physical conditions, especially for football athletes, is rarely done by trainers. Trainers in improving physical conditions such as coordination and agility are often fixated on using routine forms of training such as zigzag runs, shuttle run, shadow, and so on. But the form of Life Kinetik training is still unknown to most trainers, so it is reasonable that this exercise is not familiar and has not been used by trainers in the process of physical training, especially in football. While the conditions in other countries such as in European countries, the method of training in physical conditions has been very developed, more varied, and more leads to the use of multitasking exercises, namely through the use of Life Kinetik training methods.

A Wiener Neustadt study at 15 youth elite soccer players performed 8, 1 hour, Life Kinetic training sessions in 8 weeks, showed that Life Kinetik exercises can improve athletes' visual acuity, with Reus explaining that elite junior soccer players 
performed 15.30 minute Life Kinetik training sessions over 6 week period, can increase concentration, speed of reaction, and change in the range of errors of athletes [10]. Another study conducted by Feltes on 27 students in the education training center in Germany showed that 6-20 minutes Life Kinetik training for 4 weeks can improve motion performance and cognitive performance [10].

Based on some of these studies, it is seen that in Indonesia research is still rarely focused on improving physical conditions, especially on the ability of coordination and agility of football athletes. Therefore, the authors are interested in researching life kinetik training in improving the physical condition of football athletes. The problem that the authors want to examine in this study is whether there are differences in the effect of Life Kinetik training in improving the physical condition of football athletes, especially on the components of physical ability of coordination and agility?

\section{METHOD}

The method used in this study is an experimental method where researchers attempt to manipulate the research sample. The population in this study were male football athletes from UKM in Universitas Pendidikan Indonesia (UPI) aged between 18-19 years as many as 50 athletes. Samples taken by random selection were 40 athletes, then through assignment random samples were taken as many as 40 athletes divided into two sample groups namely experimental and control groups (conventional), each group consisted of 20 athletes. The experimental group was the group treated with Life Kinetik training, while the control group was the group given conventional training. The instrument used in this study is to measure agility using the Side Step Test, while the coordination instrument is used by the Whole Body Reaction Test. The design used in this study was a pretest-posttest control group design. The data analysis technique used in this study was the Man Whitney Test non-parametric test with the help of the SPSS for $21^{\text {st }}$ windows version program.

\section{RESULT}

The results of this study are described in the form of data from the calculation of the gain score from the results of the pretest and posttest. In the experimental group, visual coordination variables, $\mathrm{M}=0.793, \mathrm{SD}=1.546$, auditory coordination, $\mathrm{M}=0.827, \mathrm{SD}=1.603$, and agility, $\mathrm{M}=0.870$, $\mathrm{SD}=1.690$. Whereas in the conventional group visual coordination variables, $\mathrm{M}=0.608, \mathrm{SD}=1205$, auditory coordination, $\mathrm{M}=0.576, \mathrm{SD}=1.117$, and agility, $\mathrm{M}=0.730$, $\mathrm{SD}=1.430$. Furthermore, based on the results of the Man Whitney test obtained the mean rank in both groups, namely the experimental group and the conventional group, as shown in Figure 1.

Based on the results of calculations in Figure 1, it was shown that the acquisition of the mean score in the coordination variables both visual and auditory trained with Life Kinetik training, it turned out that the mean score was better than the conventional group. Furthermore, in the variable agility trained with Life Kinetik training also obtained a greater mean score than the control group trained with conventional training.

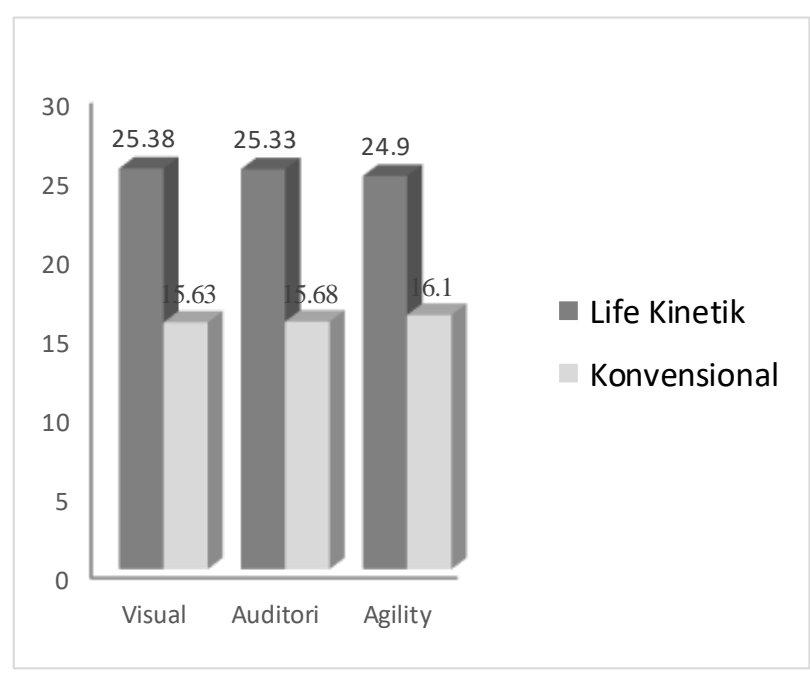

Fig. 1. Mean rank in the coordination variable (visual and auditory) and agility in the experimental group and the control group (conventional).

Next, to determine the hypothesis test that will be used in this study, testing the assumption of the data is firstly done. This is done to determine whether the data comes from a population that is normally distributed and homogeneous. Therefore, the results of testing assumptions on research data, the data from several research variables in the two groups of samples were declared abnormal and not homogeneous. Thus, the authors in conducting statistical tests of the research data using non-parametric statistical tests using the Whitney Man Test. The results of the calculation of the test are seen in Table 1.

TABLE I. Statistics TeST A

\begin{tabular}{|c|l|l|l|}
\hline \multirow{2}{*}{} & \multicolumn{2}{|c|}{ Coordination } & \multirow{2}{*}{ Agility } \\
\cline { 2 - 3 } & \multicolumn{1}{|c|}{ Visual } & \multicolumn{1}{|c|}{ Auditory } & \\
\hline Mann-Whitney U & 102.500 & 103.500 & 112.000 \\
\hline Wilcoxon W & 312.500 & 313.500 & 322.000 \\
\hline Z & -2.641 & -2.613 & -2.502 \\
\hline Asymp. Sig. (2-tailed) & .008 & .009 & .012 \\
\hline Exact Sig. [2* (1-tailed Sig.)] & $.007^{\text {b }}$ & $.008^{\text {b }}$ & $.017^{\text {b }}$ \\
\hline & \multicolumn{3}{|c}{ a. Grouping Variable: Group } \\
\hline
\end{tabular}

Based on the results of the Man Whitney statistical test in Table 1, with the formulation of the hypothesis Ho: There is no difference in the increase in the physical condition of athletes between those given Life Kinetik training and conventional training. Hi: There are differences in the improvement of the physical condition of athletes between those given Life Kinetik training and conventional training. From the test statistics table, the Asymp value is obtained. Sig. (2-tailed) on the visual coordination variable of 0.008 , auditory coordination of 0.009 , and agility of 0.012. Because of Asymp. Sig. (2-tailed) <0.05 so Ho is rejected. Thus the authors conclude that there are significant differences in the effect of Life Kinetik training and conventional training in improving the physical condition of football athletes, especially in the coordination component (visual and auditory) and agility. 
Based on the results of the calculation of the gain of the pretest and posttest scores in both groups, namely the experimental group and the conventional group, it turns out that the acquisition of the average score gain in the experimental group is greater than the conventional group. Thus this study shows that Life Kinetik training is better than conventional training in improving the physical condition of football athletes, especially in their coordination and agility abilities.

\section{DISCUSSION}

The effect of Life Kinetik training in improving physical conditions, especially coordination and agility. To discuss these findings, several expert opinions explained that Life Kinetik training is an exercise that emphasizes the combination and coordination of motion activities, cognitive challenges, and visual perception carried out through varied patterns of motion [11]. The training contains forms of exercise that emphasize complex and varied movements, so that they have a positive impact in improving physical abilities, especially coordination and agility.

Coordination is an important ability that must be possessed by athletes such as the ability of orientation, differentiation, reaction, balance, and the technical skills, this ability is very supportive in the process of mastering skills [12]. While agility is the ability to maintain or control body position while quickly changing direction during a series of movements. Agility training is a re-enforcement of motor programming through neuromuscular conditioning and neural adaptation of muscle spindles, organ tendons, and joint proprioceptors. By enhancing balance and control of body positions during movement [13]. The connection with the concept explains that agility recognizes both the cognitive and physical components. To produce coordination and agility capabilities, Life Kinetik training is very appropriate, because the training emphasizes the ability of athletes in particular to improve physical and cognitive abilities [14].

Life Kinetik Training uses several tools including the agility ladder. The agility ladder is a tool for speed training, coordination, balance, and agility [15]. The coordination and agility of football athletes with the agility ladder will be wellformed, because athletes are required to carry out varied movements and are also required to make moves by changing direction quickly. The movement turned out to have an impact on increasing hippocampal neurogenesis and resulting in improved spatial navigation and memory [16]. In addition, agility training and coordination through Life Kinetik training also result in synaptogenesis in the motor cortex and cerebellum which is useful for athletes in improving cognitive function so that athletes are required to move, change direction quickly and efficiently, strive to react quickly to tasks -works that must be performed [17]. Life Kinetik Training is able to form new synapses in the brain [18] and improve cognitive function and long-term memory processes [19], while also increasing connectivity in parts of the brain that allow involvement in tasks in the training process [19]. It is very important for football athletes to stay focused on doing their duties, always have good perceptions, and are able to make decisions quickly [20]. In connection with this statement, Patric explained that the success of athletes in sports, especially in football, requires the ability to make the right reaction in various situations so that the trainer is responsible for improving the agility of his athletes [17].

\section{CONCLUSION}

Based on the results of data analysis and the study of several works of literature, the authors conclude that there are significant differences in the effects of Life Kinetik training and conventional training in improving the physical condition of football athletes, especially in the components of coordination and agility. Life Kinetik Training turns out to be better than conventional training in improving the physical condition of football athletes. The reason is, Life Kinetik training can stimulate nerve cells and the nervous system as a whole. Football athletes are required to have good coordination on each member of the body in the process of implementing football movements that require multitasking abilities. Therefore, the author would like to recommend to trainers and athletes in sports, especially football sports, to use Life Kinetik training in each training process because this training can improve the performance of athletes especially in the quality of physical conditions.

\section{REFERENCES}

[1] T. Heinen, "Do static-sport athletes and dynamic-sport athletes differ in their visual focused attention?," Sport J., vol. 14, no. 1, pp. 1-7, 2011.

[2] A. King, Billie Jean; Braun, "Dream big 'Federation International de Football Association,"” no. April, 2016.

[3] A. N. T. Essitore, F. A. P. Erroni, C. R. C. Ortis, R. O. M. Eeusen, and C. O. L. Upo, "Coordination of Soccer Players during Preseason Training," vol. 25, no. 11, pp. 3059-3069, 2011.

[4] T. Haugen, E. Tonnessen, S. Leirstein, E. Hem, and S. Seiler, "Not quite so fast : effect of training at $90 \%$ sprint speed on maximal and repeatedsprint ability in soccer players," J. Sports Sci., vol. 32, no. December 2014, pp. 37-41, 2014.

[5] I. Gissis and C. Papadopoulos, "Strength and Speed Characteristics of Elite , Subelite, and Recreational Young Soccer Players," Res. Sport. Med., vol. 14, no. July 2013, pp. 37-41, 2006.

[6] H. Forsman, A. Gråstén, M. Blomqvist, K. Davids, and N. Konttinen, "Development of perceived competence, tactical skills , motivation, technical skills, and speed and agility in young soccer players," J. Sport. Sci. ISSN, vol. 414, no. December, pp. 1-8, 2015.

[7] B. Drust, T. Reilly, and N. T. Cable, "Physiological responses to laboratory-based soccer-specific intermittent and continuous exercise Physiological responses to laboratory-based soccer- speci $® \mathrm{c}$ intermittent and continuous exercise," J. Sports Sci., vol. 18, no. September 2013, pp. 37-41, 2013.

[8] V. Unnithan, J. White, A. Georgiou, J. Iga, V. Unnithan, J. White, A. Georgiou, J. Iga, and B. Drust, "Talent identification in youth soccer Talent identification in youth soccer," J. Sports Sci., vol. 414, no. November, 2017.

[9] T. Demirakca, V. Cardinale, S. Dehn, M. Ruf, and G. Ende, "The Exercising Brain: Changes in Functional Connectivity Induced by an Integrated Multimodal Cognitive and Whole-Body Coordination Training," Hindawi Publ. Corp. Neural Plast., vol. 2016, Arti, p. 11, 2016.

[10] Lutz, "Perform Better with Life Kinetik," Article, 2017.

[11] T. Demirakca, V. Cardinale, S. Dehn, M. Ruf, and G. Ende, "The Exercising Brain: Changes in Functional Connectivity Induced by an Integrated Multimodal Cognitive and Whole-Body Coordination Training," vol. 2016, 2016. 
[12] E. Zetou, N. Vernadakis, M. Tsetseli, and M. Michalopoulou, "The Effect of Coordination Training Program on Learning Tennis Skills," no. 4, pp. $1-8,2012$.

[13] U. Viswejan, "Impact of Ladder Training on Agility Balance and Coordination Among School Students,” pp. 229-231, 2017.

[14] J. M. Sheppard and W. B. Young, "Agility Literature Review: Classifications, Training and Testing Agility literature review: Classifications , training and testing," no. October, 2006.

[15] R. S. K. Ng, C. W. Cheung, and K. W. Sum, "Original Article Effects of 6-week agility ladder drills during recess intervention on dynamic balance performance JPES ${ }^{\circledR}$,” vol. 17, no. 1, pp. 306-311, 2017.

[16] Lynette, M. Lennemann and E. M. Kathtyn M. Sidrow, "The Influence of Agility Training on PhysiolOgical and Cognitive Performance," J. Strength Cond. Res., vol. 27, pp. 1-12, 2013.
[17] P. M. Holmberg, E. Science, and T. Oaks, "Agility Training for Experienced Athletes: A Dynamical Systems Approach,” pp. 93-98, 2009.

[18] D. Henryk, "Application Of Life Kinetik In The Process Of Teaching Technical Activities To Young Football Players," J. Kinesiol. Exerc. Sci., vol. 71, no. 25, pp. 53-63, 2015.

[19] M. Thomas, "The Effect of Different Movement Exercises on Cognitive and Motor Abilities," Sci. Res., vol. 2, no. 4, pp. 172-178, 2012.

[20] B. H. Gleason, J. B. Kramer, and M. H. Stone, "Agility Training for American Football," Strength Cond. J., vol. 37, pp. 65-71, 2015. 